\title{
Feasibility study of mindfulness-based cognitive therapy for anxiety disorders in a Japanese setting
}

\author{
Mitsuhiro Sado ${ }^{1,2^{*}} \mathbb{D}$, Sunre Park ${ }^{3,4}$, Akira Ninomiya ${ }^{1,2}$, Yasuko Sato ${ }^{5}$, Daisuke Fujisawa ${ }^{4,6}$, Joichiro Shirahase ${ }^{1,2}$ \\ and Masaru Mimura, ${ }^{1,2}$
}

\begin{abstract}
Objective: Mindfulness-based cognitive therapy (MBCT) could be a treatment option for anxiety disorders. Although its effectiveness under conditions of low pharmacotherapy rates has been demonstrated, its effectiveness under condition of high pharmacotherapy rate is still unknown. The aim of the study was to evaluate effectiveness of MBCT under the context of high pharmacotherapy rates.
\end{abstract}

Results: A single arm with pre-post comparison design was adopted. Those who had any diagnosis of anxiety disorders, between the ages of 20 and 74, were included. Participants attended 8 weekly 2 -hour-long sessions followed by 2 monthly boosters. Evaluation was conducted at baseline, in the middle, at end of the intervention, and at follow-up. The State-Trait Anxiety Inventory (STAI)-state was set as the primary outcome. Pre-post analyses with mixed-effect models repeated measures were conducted. Fourteen patients were involved. The mean age was 45.0, and 71.4\% were female. The mean change in the STAI-state at every point showed statistically significant improvement. The STAl-trait also showed improvement at a high significance level from the very early stages. The participants showed significant improvement at least one point in some other secondary outcomes.

Trial registration Retrospectively registered at the University Hospital Medical Information Network on 1st August 2013 (ID: UMIN000011347)

Keywords: Mindfulness, Anxiety disorders, Mindfulness-based cognitive behavioral therapy

\section{Introduction}

Anxiety disorders are among the most prevalent and long-term mental disorders worldwide. The prevalence rates are estimated to be $18.1 \%$ in the US [1], $6.4 \%$ in Europe [2], and $5.5 \%$ in Japan [3]. The accumulative remission rates within 8 years for social anxiety disorders, panic disorders with agoraphobia, and generalized anxiety disorders remain low, at: 31,38 , and $49 \%$, respectively [4]. The intractable feature of the condition is one of its aspects that boost prevalence.

\footnotetext{
*Correspondence: mitsusado@keio.jp

${ }^{1}$ Department of Neuropsychiatry, Keio University School of Medicine, Tokyo, Japan

Full list of author information is available at the end of the article
}

Such high prevalence considerably burdens the society. The latest disability studies $[5,6]$ revealed that anxiety disorders represent the 6th leading disease in terms of years of life lived with a disability in 2010. The burden converted into monetary cost manifests the magnitude. The societal cost of anxiety disorders rose to USD 42.3 billion in the US in 1990 [7], GBP 8.9 billion in England in 2007 [8], and JPY 2.4 trillion in Japan in 2008 [9].

Although pharmacotherapy and individualized cognitive behavior therapy (CBT) were recommended as the 1st line treatment among the clinical guidelines [10-12], more patients chose CBT if it was available. However, psychotherapists' scarcity restricts the dissemination of adequate individualized CBT. Therefore, the development of another form of psychotherapy, which is as cost effective and effective as CBT, is necessary. 
Mindfulness-based cognitive therapy (MBCT) would meet these requirements. It is a form of group psychotherapy combining the essence of CBT and mindfulnessbased stress reduction (MBSR) program, which was developed and brought into the healthcare arena by Jon Kabat-Zinn in the 1970s [13]. MBCT aims to cultivate mindfulness and intentional non-judgmental awareness in present-moment experiences [14]. This therapy could be more cost effective than individualized CBT because $\mathrm{MBCT}$ is normally provided in a group setting.

The effectiveness of MBCT has been demonstrated in various treatment areas: relapse prevention of depressive episodes [15-18], psychological distress among cancer patients [19-22], chronic pain [23], and so on [24]. Even in the area of anxiety disorder treatment, several studies have already reported significant favorable effects [2529]. However, because pharmacotherapy rates among the participants in these studies are considerably low (ranging from 0 to 39\%), its effectiveness under settings in which the vast majority of patients have already experienced pharmacotherapy (e.g., in Japan the pharmacotherapy rate among patients with anxiety disorders is $86 \%$ [30]) is still unknown. Therefore, we aimed to investigate the feasibility and effectiveness of MBCT as a pilot study with a single arm for patients with anxiety disorders.

\section{Main text \\ Method \\ Design}

A single arm study was used to test MBCT's feasibility and effectiveness with a pre-post comparison. The study was conducted between March 2013 and September 2014.

\section{Ethics approval and consent to participate}

This study was approved by the ethical committee at Keio University School of Medicine and registered at the University Hospital Medical Information Network on 1st August 2013 (ID: UMIN000011347).

\section{Participants}

Inclusion criteria for this study were: (1) any diagnosis of panic disorder, social anxiety disorder, obsessive compulsive disorder, or generalized anxiety disorder using the Diagnostic and Statistical Manual of Mental Disorders 4th edition; (2) aged between 20 and 74 years; and (3) able to provide consent in writing. The exclusion criteria were: (1) any past history of substance-related disorders/ manic or psychotic episode/receiving mindfulness-based intervention, (2) impairment in cognitive function, (3) antisocial personality disorder, (4) severe suicidal ideation, and (5) expected difficulty in following up 4 months after the start of the intervention.

\section{Procedure}

The participants were recruited from the Department of Neuropsychiatry, Keio University Hospital. After providing written consent, they attended an 8-week course of MBCT for anxiety, followed by 2 monthly booster sessions. Evaluation was conducted before the intervention (0 weeks) (T0), during it (4 weeks) (T1), at its end (8 weeks) (T2), and during the follow-up periods (1 month (T3) and 2 months after the completion of the program (T4)).

\section{Intervention}

Because the original MBCT [13] targets relapse prevention for depression, we made minimal modifications to the original program in order to ensure that it fits with anxiety disorders. Specifically, we revised the psychoeducational part in Session 4 so that it would be relevant to anxiety disorders. The details of the program are shown in Table 1.

This program consists of 8 weekly 2-hour-long sessions. Each session consists of three parts: (1) practicing meditation and yoga, (2) sharing experiences, and (3) psychoeducational portions. The participants were encouraged to practice daily for $30 \mathrm{~min}$ to $1 \mathrm{~h}$ at home with audio $C D$ instructions and perform other exercises such as monitoring positive or negative feelings.

The program was led by a psychiatrist (MS) and a nurse/clinical psychologist (SP), both of whom had practiced mindful meditation for more than 2 years with experience in attending MBSR and MBCT retreats.

\section{Outcomes}

We used the following scales to measure outcomes, all of which had already been validated in Japanese.

Primary We set the State-Trait Anxiety Inventory (STAI)-state as the primary outcome. The STAI is a commonly used measure of state and trait anxiety [31].

Secondary We also used the following scales for secondary outcomes: the STAI-trait, 6-item Kessler Psychological Distress Scale (K-6), Center for Epidemilogic Studies Depression Scale (CES-D), EuroQol 5 Dimension (EQ-5D), Five Facet Mindfulness Questionnaire (FFMQ), 36-Item Short-Form Health Survey (SF-36), Mobility Inventory for Agoraphobia (MIA), and Liebowitz Social Anxiety Scale (LSAS). The details of each scale are as follows.

K-6 The K6 scale was designed to be sensitive to the threshold for the clinically significant range of the distribution of nonspecific distress in an effort to 
Table 1 Contents of the program

\begin{tabular}{|c|c|c|}
\hline Session & Theme & Contents \\
\hline \multirow[t]{3}{*}{1} & Automatic pilot & Psychoeducation: what is mindfulness \\
\hline & & Exercise: mindfulness eating ("Raisin exercise")/body scan \\
\hline & & Homework: mindfulness of a routine activity/body scan \\
\hline \multirow[t]{3}{*}{2} & Dealing with barriers & Psychoeducation: association of mood and thoughts \\
\hline & & Exercise: thoughts and feelings exercise/body scan/mindful breathing meditation \\
\hline & & Homework: body scan/breathing meditation/pleasant events calendar \\
\hline \multirow[t]{3}{*}{3} & Mindfulness of the breath & Psychoeducation: awareness of mind wandering and focuing on the breath \\
\hline & & Exercise: breathing meditation/gentle yoga/mindful walking \\
\hline & & Homework: breathing meditation/gentle yoga/mindful walking/unpleasant events calendar \\
\hline \multirow[t]{3}{*}{4} & Staying present & Psychoeducation: staying present/about anxiety symptoms ${ }^{\mathrm{a}}$ \\
\hline & & Exercise: meditation of sounds and thoughts/breathing meditation \\
\hline & & Homework: meditation of sounds and thoughts/breathing meditation/3-min breathing space \\
\hline \multirow[t]{3}{*}{5} & Allowing/letting be & Psychoeducation: exploring difficulty \\
\hline & & Exercise: breathing meditation/meditation of sounds and thoughts/exploring difficulty \\
\hline & & $\begin{array}{l}\text { Homework: breathing meditation/meditation of sounds and thoughts/exploring difficulty/3-min } \\
\text { breathing space }\end{array}$ \\
\hline \multirow[t]{3}{*}{6} & Thoughts are not facts & Psychoeducation: cognitive biases \\
\hline & & Exercise: breathing meditation/meditation of sounds and thoughts/exploring difficulty \\
\hline & & $\begin{array}{l}\text { Homework: breathing meditation/meditation of sounds and thoughts/exploring difficulty/3-min } \\
\text { breathing space }\end{array}$ \\
\hline \multirow[t]{3}{*}{7} & How can I best take care of myself? & Psychoeducation: choosing functional behaviors/behavioral activation/identifying triggers \\
\hline & & Exercise: mindfulness meditation of sounds and thoughts/breathing meditation \\
\hline & & $\begin{array}{l}\text { Homework: meditation of sounds and thoughts/breathing meditation/3-min breathing space }+ \text { action } \\
\text { plan }\end{array}$ \\
\hline \multirow[t]{2}{*}{8} & $\begin{array}{l}\text { Using what has been learned to } \\
\text { deal with future mood }\end{array}$ & $\begin{array}{l}\text { Personal reflections of course/plans for future practice and strategies for maintaining momentum/ } \\
\text { farewell }\end{array}$ \\
\hline & & Exercise: body scan/breathing meditation \\
\hline
\end{tabular}

a The lecture relevant to depression was replaced by that about anxiety in session 4

maximize its ability to discriminate cases of serious mental illness from non-cases [32].

$C E S-D$ The CES-D is a short self-report scale designed to measure depressive symptomatology among the general population [33]. The scale contains 20 items that ask how often over the past week the patients experienced symptoms associated with depression.

$E Q-5 D$ EQ-5D is a standardized instrument for use as a measure of health outcomes [34]. It provides a simple descriptive profile and a single index value for health status.

FFMQ The FFMQ is based on a factor analytic study of five independently developed mindfulness questionnaires [35]. The five facets are observing, describing, acting with awareness, the non-judging of inner experience, and nonreactivity to inner experience.

SF-36 The SF-36 is a set of generic, coherent, and easily administered quality-of-life measures. These measures rely on patient self-report [36]. It consists of eight sections: vitality, physical functioning, bodily pain, general health perceptions, physical role functioning, emotional role functioning, social role functioning, and mental health $[37,38]$.

$M I A$ The MIA is a measurement of self-reported agoraphobic avoidance behavior and frequency of panic attacks [39]. Respondents rate 26 items using Likert-type scales ranging from 1 (never avoid) to 5 (always avoid) to indicate how much they avoid various situations due to anxiety or discomfort when they are accompanied by a trusted companion and when they are alone.

LSAS The LSAS is an instrument used to assess the range of social interactions and performance situations that a patient fears; it assists in the diagnosis of social anxiety disorder [32]. The scale features 24 items, which are divided into two subscales. Of these, 13 questions relate to performance anxiety and 11 to social situations.

\section{Analyses}

Changes in mean scores between the baseline and each observational period for each scale were tested with mixed-effect models, repeated-measures, and intention-to-treat analyses. Age, sex, and intervention were 
imputed into the model as coefficients. A 5\% significance level was adopted for all statistical analyses. STATA ver.15 was used to conduct the statistical analysis.

\section{Results}

\section{Basic participant characteristics}

Fourteen patients were involved in the research. As shown in Table 2, mean age (standard deviation: sd) was 45.0 (14.1), and $71.4 \%$ were female. With respect to primary diagnosis, six participants had panic disorders, while five and three had social anxiety disorder and obsessive compulsive disorder, respectively. Average treatment duration at the start of the intervention was 13.4 years (7.4) and the rate of pharmacotherapy use was 93\% (71.4\% and 50.0\% used antidepressants and benzodiazepine, respectively). All but one of the participants completed the program and the average number of program attendance was 7.4 (1.1). The reason for dropout was the deterioration of respiratory symptoms that were originally comorbid.

\section{Primary outcome}

As described in Table 3, the mean change (sd) from baseline in STAI-state at every point showed statistically significant improvements: $-6.14(2.70)$ at T1, $-11.66(2.78)$ at $\mathrm{T} 2,-8.12(2.78)$ at $\mathrm{T} 3$, and $-6.58(2.78)$ at $\mathrm{T} 4$.

\section{Secondary outcome}

As shown in Table 3, significant improvements were observed in multifarious scales. For STAI-trait, improvement was observed from the very early stages with high significance levels and continued until 2 months after the completion of the intervention. With respect to K-6, the participants showed significant improvements

Table 2 Baseline characteristics of the participants

\begin{tabular}{lll}
\hline Characteristics & Mean/n & sd/\% \\
\hline Age & 45.0 & 14.1 \\
Gender (female) & 10 & 71.4 \\
Diagnosis & & \\
Panic disorder & 6 & 42.9 \\
SAD & 5 & 35.7 \\
OCD & 3 & 21.4 \\
Duration from onset (years) & 13.4 & 7.4 \\
Medication & 13 & 92.9 \\
Antidepressants & 10 & 71.4 \\
Benzodiazepine & 7 & 50.0 \\
Mood stabilizer & 2 & 14.3 \\
Antipsychotics & 2 & 14.3 \\
Frequency of attendance & 7.4 & 1.1 \\
\hline
\end{tabular}

$S A D$ social anxiety disorder, $O C D$ obsessive compulsive disorder post-treatment, but these disappeared during follow-up. Although the total score did not show any change, significant improvements were noted on an FFMQ subscale (i.e., non-judgment) immediately and also at 1 month post-treatment. Moreover, the trend-level improvement in another subscale (i.e., awareness) at 2 months posttreatment was acknowledged.

With regard to the disease-specific scales, the MIA (AAC) score indicated significant improvements at 2 month follow-up, while only improvement trend was detected in MIA (AAL) at the end of the follow-up. No improvement was observed in LSAS, specifically, among the participants with social anxiety disorders.

\section{Discussion}

To the best of our knowledge, this is the first study in Japan to evaluate the applicability and feasibility of the $\mathrm{MBCT}$ for anxiety disorders. The present results indicate that it would favorably affect the symptoms of anxiety disorders. The quite low attrition rate also demonstrated its feasibility even in settings under which pharmacotherapy had already been provided to the vast majority of participants.

The improvement in STAI-state with a high significance level that was observed even post-treatment indicates that the efficacy of MBCT would be sustained, even after the intervention. Another surprising result was that STAI-trait similarly improved significantly. This means the MBCT has the potential to remedy the trait that would affect the onset and continuity of anxiety symptoms from the very early stages. This might represent the peculiarity of mindfulness, which aims to transform the attitude toward unpleasant events rather than to remove the unpleasant experiences themselves.

We covered only two disease-specific scales: agoraphobia and panic attack (MIA) and social phobia (LSAS) due to the constraints of scale availability. The fact that MIA (AAC) showed significant immediate and 2-monthpost-treatment improvements indicates that MBCT has the potential to be effective even for disease-specific symptoms.

Attention should be paid to the interpretation of the results of the FFMQ. The FFMQ is composed of five factors, and is supposed to converge at two higher factors: "self-regulated attention" and "orientation to experience" [40]. Although a previous study showed significant changes in all FFMQ factors pre- and postintervention in the MBCT group [41], no changes were detected in this study except for "non-judging." As indicated in previous studies, although numerous validation studies have been conducted to measure mindfulness, the results appear to vary [42]. The discrepancy 
Table 3 Outcomes scores at each assessment point with comparison to baseline

\begin{tabular}{|c|c|c|c|c|c|c|c|c|c|c|c|}
\hline \multicolumn{12}{|c|}{ Mean score at baseline and mean differences compared to baseline } \\
\hline & \multirow[t]{2}{*}{$\mathbf{n}$} & \multicolumn{2}{|c|}{ Baseline } & \multicolumn{2}{|l|}{4 week } & \multicolumn{2}{|l|}{8 week } & \multicolumn{2}{|l|}{12 week } & \multicolumn{2}{|l|}{16 week } \\
\hline & & Mean & se & Mean difference & se & Mean difference & se & Mean difference & se & Mean difference & se \\
\hline STAl-state & 14 & 52.6 & 2.8 & -6.14 & 2.70 & -11.66 & 2.78 & -8.12 & 2.78 & -6.58 & 2.78 \\
\hline$P$ value & & & & 0.02 & & $<0.001$ & & $<0.01$ & & 0.02 & \\
\hline STAl-trait & 14 & 55.9 & 3.0 & -3.86 & 1.85 & -6.55 & 1.90 & -4.86 & 1.90 & -3.93 & 1.90 \\
\hline$P$ value & & & & 0.04 & & $<0.01$ & & 0.01 & & 0.04 & \\
\hline $\mathrm{K}-6$ & 14 & 8.6 & 1.6 & -1.07 & 1.17 & -2.68 & 1.20 & -1.68 & 1.20 & 0.16 & 1.20 \\
\hline$P$ value & & & & 0.36 & & 0.03 & & 0.16 & & 0.89 & \\
\hline CESD & 14 & 17.7 & 3.0 & -0.71 & 2.03 & -1.46 & 2.09 & -3.85 & 2.09 & 1.69 & 2.09 \\
\hline$P$ value & & & & 0.73 & & 0.48 & & 0.07 & & 0.42 & \\
\hline SF36 PCS & 14 & 54.1 & 2.8 & -0.57 & 2.02 & 1.68 & 2.07 & 0.52 & 2.07 & 1.32 & 2.07 \\
\hline$P$ value & & & & 0.78 & & 0.42 & & 0.80 & & 0.53 & \\
\hline SF36MCS & 14 & 41.4 & 3.6 & -2.17 & 2.18 & 2.11 & 2.25 & 2.27 & 2.25 & -1.33 & 2.25 \\
\hline$P$ value & & & & 0.32 & & 0.35 & & 0.31 & & 0.55 & \\
\hline SF36 RCS & 14 & 42.5 & 4.3 & 3.13 & 2.84 & 3.03 & 2.92 & 4.50 & 2.92 & 2.29 & 2.92 \\
\hline$P$ value & & & & 0.27 & & 0.30 & & 0.12 & & 0.43 & \\
\hline FFMQ (total) & 14 & 110.4 & 4.9 & -1.42 & 2.25 & 2.51 & 2.31 & 0.96 & 2.31 & -1.17 & 2.31 \\
\hline$P$ value & & & & 0.53 & & 0.28 & & 0.68 & & 0.61 & \\
\hline FFMQ (observe) & 14 & 22.6 & 1.5 & -0.93 & 0.99 & 0.07 & 1.01 & 0.14 & 1.01 & 0.77 & 1.01 \\
\hline$P$ value & & & & 0.35 & & 0.94 & & 0.89 & & 0.45 & \\
\hline FFMQ (noreact) & 14 & 16.6 & 1.7 & -0.79 & 0.84 & 0.93 & 0.87 & 0.81 & 0.87 & 0.39 & 0.87 \\
\hline$P$ value & & & & 0.35 & & 0.28 & & 0.35 & & 0.65 & \\
\hline FFMQ (nonjudgement) & 14 & 23.9 & 2.0 & 2.00 & 1.17 & 2.62 & 1.21 & 2.54 & 1.21 & 0.77 & 1.21 \\
\hline$P$ value & & & & 0.09 & & 0.03 & & 0.04 & & 0.52 & \\
\hline FFMQ (descrive) & 14 & 22.9 & 1.5 & -1.18 & 0.84 & 0.57 & 0.87 & -0.96 & 0.87 & -1.04 & 0.87 \\
\hline$P$ value & & & & 0.16 & & 0.51 & & 0.27 & & 0.23 & \\
\hline FFMQ (awareness) & 14 & 24.5 & 1.6 & -0.52 & 1.11 & -1.69 & 1.15 & -1.58 & 1.15 & -2.07 & 1.15 \\
\hline$P$ value & & & & 0.64 & & 0.14 & & 0.17 & & 0.07 & \\
\hline EQ-5D & 14 & 0.79 & 0.04 & 0.01 & 0.03 & 0.02 & 0.03 & 0.03 & 0.03 & 0.04 & 0.03 \\
\hline$P$ value & & & & 0.79 & & 0.41 & & 0.22 & & 0.09 & \\
\hline MIA (AAC) & 6 & 1.88 & 0.29 & -0.08 & 0.09 & -0.18 & 0.09 & -0.13 & 0.09 & -0.24 & 0.09 \\
\hline$P$ value & & & & 0.39 & & 0.05 & & 0.14 & & $<0.01$ & \\
\hline $\mathrm{MIA}(\mathrm{AAL})$ & 6 & 2.24 & 0.49 & -0.02 & 0.14 & -0.15 & 0.14 & -0.05 & 0.14 & -0.25 & 0.14 \\
\hline$P$ value & & & & 0.87 & & 0.28 & & 0.71 & & 0.07 & \\
\hline MIA (panic attack 1 weeks) & 6 & 2.83 & 2.44 & -0.17 & 1.19 & -1.67 & 1.19 & -2.17 & 1.19 & -1.67 & 1.19 \\
\hline$P$ value & & & & 0.89 & & 0.16 & & 0.07 & & 0.16 & \\
\hline MIA (panic attack 3 weeks) & 6 & 5.83 & 4.85 & -1.00 & 1.72 & -3.33 & 1.72 & -2.83 & 1.72 & -2.50 & 1.72 \\
\hline$P$ value & & & & 0.56 & & 0.05 & & 0.10 & & 0.15 & \\
\hline LSAS & 5 & 73.40 & 13.41 & -12.00 & 6.81 & -3.63 & 7.42 & -7.38 & 7.42 & -9.13 & 7.42 \\
\hline$P$ value & & & & 0.08 & & 0.63 & & 0.32 & & 0.22 & \\
\hline
\end{tabular}

between the previous and current studies possibly represents the nature of this scale. In addition, the discrepancy could be due to the small sample size of the current study. No, or quite limited, specific measures for anxiety in the CES-D, EQ-5D, and SF-36 would be a reason why no significant changes were observed in scores on these scales. 


\section{Limitations}

This study has some limitations. The sample size was too small to conduct subgroup analyses between different types of anxiety disorders. This also affected the generalizability of the results. The other limitation was that the study was performed with a single arm prepost design. Therefore, it is necessary to conduct randomized controlled studies to accurately evaluate its effectiveness in future research.

\section{Abbreviations}

AAC: Avoidance Accompanied Scale; AAL: Avoidance Alone Scale; CBT: cognitive behavior therapy; CES-D: Center for Epidemiologic Studies Depression Scale; EQ-5D: EuroQol 5 Dimension; FFMQ: Five Facet Mindfulness Questionnaire; K-6: the 6-item Kessler Psychological Distress Scale; LSAS: the Liebowitz Social Anxiety Scale; MBCT: mindfulness-based cognitive therapy; MBSR: mindfulness-based stress reduction; MIA: the Mobility Inventory for Agoraphobia; sd: standard deviation; SF-36: the 36-Item Short-Form Health Survey; STAI: the State-Trait Anxiety Inventory.
\end{abstract}

\section{Authors' contributions}

MS conceived and designed the study. MS drafted the study protocol. MS and SP organized and supervised the study implementation, and MS drafted the manuscript. SP, AN, JS, and MM refined the study protocol and implementation. MS, SP, and YS intervened with the participants. MS and AN conducted the statistical analyses. MS, AN, DF, JS and MM interpreted the results. MS drafted the grant proposal and was responsible for the study implementation. MS was responsible for the study management. SP, YS, and AN collected data. All authors critically reviewed the manuscript for content and approved the final version. MS and AN had full access to all of the data throughout the study and take responsibility for the integrity of the data and the accuracy of the analysis. All authors read and approved the final manuscript.

\section{Author details \\ ${ }^{1}$ Department of Neuropsychiatry, Keio University School of Medicine, Tokyo, Japan. ${ }^{2}$ Center for Stress Research, Keio University, Tokyo, Japan. ${ }^{3}$ Faculty of Nursing and Medicine Care, Keio University, Tokyo, Japan. ${ }^{4}$ Palliative Care Center, Keio University Hospital, Tokyo, Japan. ${ }^{5}$ Department of Nursing, National Hospital Organization Tokyo Medical Center, Tokyo, Japan. ${ }^{6}$ Division of Patient Safety, Department of Neuropsychiatry, Keio University School of Medicine, Tokyo, Japan.}

\section{Acknowledgements}

Not applicable.

\section{Competing interests}

The authors declare that they have no competing interests.

\section{Availability of data and materials}

The datasets used and/or analyzed during the current study are available from the corresponding author upon reasonable request.

\section{Consent to publish}

Not applicable.

\section{Ethics approval and consent to participate}

This study was approved by the ethical committee at Keio University School of Medicine (reference: 2012-440). The identification number of the clinical trial registry system at the University Hospital Medical Information Network was UMIN000011347.

\section{Funding}

This research was conducted with the assistance of a fund for the promotion of science from Keio University (H24 KEIO-GAKUSHIN-KOJIN 004163). The fund body was not involved in any of the following processes: the development of the study design and protocol; data collection, analysis, or interpretation; and the writing of the manuscript.

\section{Publisher's Note}

Springer Nature remains neutral with regard to jurisdictional claims in published maps and institutional affiliations.

Received: 20 July 2018 Accepted: 28 August 2018

Published online: 06 September 2018

\section{References}

1. Kessler RC. Prevalence, severity, and comorbidity of twelve-month DSMIV disorders in the National Comorbidity Survey replicaton. Arch Gen Psychiatry. 2005;62(6):617-27.

2. Alonso J. Prevalence of mental disorders in Europe: results from the Epidemiology of Mental Disorders (ESEMeD) Project. Acta Psychiatr Scand Suppl. 2004;420:21-7

3. Kawakami N, Takeshima T, Ono Y, Uda H, Hata Y, Nakane Y, et al. Twelve-month prevalence, severity, and treatment of common mental disorders in communities in Japan: preliminary finding from the World Mental Health Japan Survey 2002-2003. Psychiatry Clin Neurosci. 2005;59(4):441-52.

4. Yonkers KA, Bruce SE, Dyck IR, Keller MB. Chronicity, relapse, and illnesscourse of panic disorder, social phobia, and generalized anxiety disorder: findings in men and women from 8 years of follow-up. Depress Anxiety. 2003;17(3):173-9.

5. Murray CJL. Choosing indicators for the health-related SDG targets. Lancet. 2015;386(10001):1314-7.

6. Baxter AJ, Vos T, Scott KM, Ferrari AJ, Whiteford HA. The global burden of anxiety disorders in 2010. Psychol Med. 2014;44(11):2363-74.

7. Greenberg PE, Sisitsky T, Kessler RC, Finkelstein SN, Berndt ER, Davidson JR, et al. The economic burden of anxiety disorders in the 1990s. J Clin Psychiatry. 1999;60(7):427-35.

8. McCrone P. Paying the price: the cost of mental health care in England to 2026. London: King's Fund; 2008.

9. Sado M, Takechi S, Inagaki A, Fujisawa D, Koreki A, Mimura M, et al. Cost of anxiety disorders in Japan in 2008: a prevalence-based approach. BMC Psychiatry. 2013;13:338.

10. Generalised anxiety disorder and panic disorder (with or without agoraphobia) in adults: management in primary, secondary and community care (partial update) [Internet]. National Collaborating Centre for Mental Health Commissioned by NICE; 2011. http://www.nice.org.uk/nicemedia/ live/13314/52667/52667.pdf. Accessed 1 July 2018.

11. Social anxiety disorder: recognition, assessment and treatment [Internet]. National Collaborating Centre for Mental Health Commissioned by NICE; 2013. https://www.nice.org.uk/guidance/cg159/resources/social-anxie ty-disorder-recognition-assessment-and-treatment-pdf-35109639699397. Accessed 1 July 2018.

12. Obsessive-compulsive disorder and body dysmorphic disorder: treatment [Internet]. National Collaborating Centre for Mental Health Commissioned by NICE; 2005. https://www.nice.org.uk/guidance/cg31/resou rces/obsessivecompulsive-disorder-and-body-dysmorphic-disorder-treat ment-pdf-975381519301. Accessed 1 July 2018.

13. Segal Z, Williams JM, Teasdale J. Mindfulness-based cognitive therapy for depression. A new approach to preventing relapse. New York: Guilford Publications; 2002.

14. Kabat-Zinn J. Full catastrophe living: using the wisdom of your body and mind to face stress, pain, and illness. New York: Delacorte Press; 1990.

15. Teasdale JD, Segal ZV, Williams JM, Ridgeway VA, Soulsby JM, Lau MA. Prevention of relapse/recurrence in major depression by mindfulness-based cognitive therapy. J Consult Clin Psychol. 2000;68(4):615-23.

16. Ma SH, Teasdale JD. Mindfulness-based cognitive therapy for depression: replication and exploration of differential relapse prevention effects. J Consult Clin Psychol. 2004;72(1):31-40.

17. Kuyken W, Byford S, Taylor RS, Watkins E, Holden E, White K, et al. Mindfulness-based cognitive therapy to prevent relapse in recurrent depression. J Consult Clin Psychol. 2008;76(6):966-78. 
18. Kuyken W, Hayes R, Barrett B, Byng R, Dalgleish T, Kessler D, et al. Effectiveness and cost-effectiveness of mindfulness-based cognitive therapy compared with maintenance antidepressant treatment in the prevention of depressive relapse or recurrence (PREVENT): a randomised controlled trial. Lancet. 2015;386(9988):63-73.

19. Zainal NZ, Booth S, Huppert FA. The efficacy of mindfulness-based stress reduction on mental health of breast cancer patients: a meta-analysis. Psychooncology. 2013;22(7):1457-65.

20. Zhang J, Xu R, Wang B, Wang J. Effects of mindfulness-based therapy for patients with breast cancer: a systematic review and meta-analysis. Complement Ther Med. 2016;26:1-10.

21. Haller H, Winkler MM, Klose P, Dobos G, Kummel S, Cramer H. Mindfulness-based interventions for women with breast cancer: an updated systematic review and meta-analysis. Acta Oncol. 2017;56(12):1665-76.

22. Huang HP, He M, Wang HY, Zhou M. A meta-analysis of the benefits of mindfulness-based stress reduction (MBSR) on psychological function among breast cancer (BC) survivors. Breast Cancer. 2016;23(4):568-76.

23. Hilton L, Hempel S, Ewing BA, Apaydin E, Xenakis L, Newberry S, et al. Mindfulness meditation for chronic pain: systematic review and metaanalysis. Ann Behav Med. 2017;51(2):199-213.

24. Khoury B, Lecomte T, Fortin G, Masse M, Therien P, Bouchard V, et al. Mindfulness-based therapy: a comprehensive meta-analysis. Clin Psychol Rev. 2013;33(6):763-71.

25. Craigie MA, Rees C, Marsh A, Nathan P. Mindfulness-based cognitive therapy for generalized anxiety disorder: a preliminary evaluation. Behav Cogn Psychother. 2008;36(5):553-68.

26. Kim B, Lee SH, Kim YW, Choi TK, Yook K, Suh SY, et al. Effectiveness of a mindfulness-based cognitive therapy program as an adjunct to pharmacotherapy in patients with panic disorder. J Anxiety Disord. 2010;24(6):590-5

27. Evans S, Ferrando S, Findler M, Stowell C, Smart C, Haglin D. Mindfulnessbased cognitive therapy for generalized anxiety disorder. J Anxiety Disord. 2008:22(4):716-21.

28. Yook K, Lee SH, Ryu M, Kim KH, Choi TK, Suh SY, et al. Usefulness of mindfulness-based cognitive therapy for treating insomnia in patients with anxiety disorders: a pilot study. J Nerv Ment Dis. 2008;196(6):501-3.

29. Piet J, Hougaard E, Hecksher MS, Rosenberg NK. A randomized pilot study of mindfulness-based cognitive therapy and group cognitivebehavioral therapy for young adults with social phobia. Scand J Psychol. 2010;51(5):403-10.
30. Uchida H, Suzuki T, Mamo DC, Mulsant BH, Kikuchi T, Takeuchi H, et al. Benzodiazepine and antidepressant use in elderly patients with anxiety disorders: a survey of 796 outpatients in Japan. J Anxiety Disord. 2009;23(4):477-81.

31. Spielberger CD, Gorsuch RL, Lushene R, Vagg PR, Jacobs GA. Manual for the State-Trait Anxiety Inventory. Palo Alto, CA: Consulting Psychologists Press; 1983.

32. Kessler RC, Barker PR, Colpe LJ, Epstein JF, Gfroerer JC, Hiripi E, et al. Screening for serious mental illness in the general population. Arch Gen Psychiatry. 2003;60(2):184-9.

33. Radloff LS. The CES-D Scale: a self-report depression scale for research in the general population. Appl Psychol Meas. 1977;1:385-401.

34. Brooks R. EuroQol: the current state of play. Health Policy. 1996;37(1):53-72.

35. Baer RA, Smith GT, Hopkins J, Krietemeyer J, Toney L. Using self-report assessment methods to explore facets of mindfulness. Assessment. 2006;13(1):27-45

36. Health R. 36-Item Short Form Survey Santa Monica: RAND Health. https ://www.rand.org/health/surveys_tools/mos/36-item-short-form.html. Accessed 1 July 2018

37. Brazier JE, Harper R, Jones NM, O'Cathain A, Thomas KJ, Usherwood T, et al. Validating the SF-36 health survey questionnaire: new outcome measure for primary care. BMJ. 1992;305(6846):160-4.

38. Fukuhara S, Ware JE Jr, Kosinski M, Wada S, Gandek B. Psychometric and Clinical tests of validity of the Japanese SF-36 health survey. J Clin Epidemiol. 1998;51(11):1045-53.

39. Chambless DL, Caputo GC, Jasin SE, Gracely EJ, Williams C. The mobility inventory for agoraphobia. Behav Res Ther. 1985;23(1):35-44.

40. Tran US, Gluck TM, Nader IW. Investigating the Five Facet Mindfulness Questionnaire (FFMQ): construction of a short form and evidence of a two-factor higher order structure of mindfulness. J Clin Psychol. 2013;69(9):951-65.

41. Koszycki D, Thake J, Mavounza C, Daoust JP, Taljaard M, Bradwejn J. Preliminary investigation of a mindfulness-based intervention for social anxiety disorder that integrates compassion meditation and mindful exposure. J Altern Complement Med. 2016;22(5):363-74.

42. ParkT, Reilly-Spong M, Gross CR. Mindfulness: a systematic review of instruments to measure an emergent patient-reported outcome (PRO). Qual Life Res. 2013;22(10):2639-59.
Ready to submit your research? Choose BMC and benefit from:

- fast, convenient online submission

- thorough peer review by experienced researchers in your field

- rapid publication on acceptance

- support for research data, including large and complex data types

- gold Open Access which fosters wider collaboration and increased citations

- maximum visibility for your research: over $100 \mathrm{M}$ website views per year

At BMC, research is always in progress.

Learn more biomedcentral.com/submissions 